\title{
Review of Mary S. Morgan's The world in the model: how economists work and think. Cambridge University Press, 2012, 435 pp.
}

\author{
ROBERT SUGDEN \\ University of East Anglia
}

The world in the model is a distillation of fifteen years of concentrated work by a major philosopher and historian of economics. Mary Morgan's topic is how economists use models. Her aim is "to offer both a history of the naturalization of modelling in economics and a naturalized philosophy of science for economics". Recognising that "science is messy", she presents "a series of historical case studies through which the philosophical commentary runs". She describes this commentary as an account of modelling "as a way of doing science that has its own rationale just as do other modes of science" (pp. xv-xvi).

This is a long book, written with great clarity and rich in historical detail. The opening chapter, which sets out the agenda for the rest of the book, includes discussions of Quesnay's Tableau Economique, arguably the first economic model, and of Frisch's model of macroeconomic cycles. The following chapters link methodological themes with extended historical studies of modelling practice. These studies feature Ricardo's model of the distribution of the economic product, the Edgeworth Box, the concept of the rational economic man, the Newlyn-Phillips Machine, the IS-LM model, the supply and demand diagram, and the Prisoner's Dilemma.

As a practising economic modeller with only limited knowledge of the history of economics, I found the case studies fascinating and illuminating. I particularly enjoyed Morgan's accounts of David Ricardo and of the Newlyn-Phillips Machine.

In conventional histories of economic thought, Ricardo is often presented as the first formal economic theorist. His approach is seen as substituting dry but mathematically tractable abstractions in place of Adam Smith's wide-ranging interest in actual economic life. His style of reasoning-working through numerical examples rather than general qualitative relationships-is seen as clumsy, or perhaps as a necessary concession to his readers' lack of mathematical sophistication. Morgan 
gives us a very different picture, in which Ricardo's theory of production and distribution becomes "Ricardo's model farm" (pp. 73-79). Ricardo was not just a successful City financier who turned to economics. Following a traditional English route to social status, he bought a country estate and took an interest in farming. Morgan shows that Ricardo's numerical examples of production processes were similar to contemporary reports of agricultural experiments by gentlemanfarmers. She suggests that Ricardo's modelling, far from being dry and abstract, was a generalisation of agricultural experimentation; his modelling strategy was to represent a whole economy as a single farm.

The hydraulic model of a macroeconomic system, first constructed by Newlyn and Phillips at the University of Leeds in 1949, is justly famous. In economics, it is usually seen as a curiosity and as an imaginative teaching aid. In computing, it is seen as one of the first analogue computers. In philosophy of science, it is an example of how a model can have a physical rather than mathematical existence, while being built out of materials very different from those of the reality that it represents. Its history is a good story, and Morgan tells it well. She shows that, in building their Machine, Newlyn and Phillips had to solve fundamental problems in macroeconomic theory concerning the integration of stocks and flows. They were able to do this because, unlike other macroeconomists of the time, they were working in the domain of hydraulics rather than in that of two-dimensional diagrams of mathematical equations.

The philosophical commentary on these case studies comprises both a history of the role that models have in fact played in economics and a methodological account of the practice of modelling. In Morgan's history, models became central to the practice of economic science only from the 1930s. Classical economics was based on the notion of 'universal laws'. Two new "styles of reasoning" began to emerge in the late nineteenth century, both of which were associated with the use of mathematics - the "method of mathematical postulation and proof" and the method of modelling (p. 18). Morgan recognises that the dividing line between these two styles is not easy to draw, and one might disagree with some of her categorisations. (For example, she presents Walras as a practitioner of mathematical postulation and proof, but his representation of a whole economy as a single auction might be viewed as a masterpiece of economic modelling.) In any event, Morgan is in no doubt that the method of modelling has come to dominate theoretical 
economics. Models and modelling "are endemic at every level" of economics (p. 2); they have become "the primary way of doing economic science" (p. 379). Modern economics "has become a social science largely dependent on small mathematical or diagrammatic models, each separately representing different bits of the economy and each treated largely independently of the others" (pp. 378-379).

Morgan's account of what models are, and of what modelling is, starts from an attempt to distinguish models from other forms of representation. For Morgan, the essential distinction is that models are "working objects" (p. 380); they provide resources for reasoning. She treats the concept of manipulation as fundamental to modelling: "representations only become models when they have the resources for manipulation" (p. 27).

Morgan repeatedly declares that models have two uses: "Models are objects to enquire into and to enquire with: economists enquire into the world of the economic model, and use them to enquire with into the economic world that the model represents" (p. 217). However, as the title of her book hints, she has more to say about the first of these uses than about the second. Summarising how economists use models, she says: "they [economists] ask questions, use the resources of the model to demonstrate something, and tell stories in the process" (pp. 217-218). This combination of activities is treated as "a kind of experiment" (p. 31); the similarity between modelling and experimenting marks a major difference from the method of mathematical postulation and proof (p. 33).

Morgan fleshes out this account by presenting "reasoning with models" as involving four steps. Step 1 is to construct a model relevant for some problem of interest. Step 2 is to ask questions about "something in the model or in the world". Step 3 is to "demonstrate the answer to the questions using the model's resources". This is where manipulation comes in: the answer is arrived at by manipulating the model. Step 4 is to add a "narrative" that "accompanies the demonstration to link the answers back to the questions and to their domains" (p. 225). The implication seems to be that if the questions are about the world the answers have to come through the narrative (since the model can demonstrate only what is true of itself).

'Manipulation' and 'demonstration' seem to be almost interchangeable concepts in Morgan's account. She says that a model comes with associated "rules for reasoning", which are constrained 
by "the kind of stuff that the model is made from, or language it is written in, or the format it has". These rules "effectively determine the economist's valid manipulation or use of that model". For mathematical models, these are typically rules of geometry or algebra; for the NewlynPhillips Machine, they are rules of hydraulics (p. 26).

Take the case of Frisch's model. The version discussed by Morgan consists of three dynamic equations linking the rate of production of consumption goods, the rate of production of capital goods and the stock of capital goods. These equations can be solved to give the time paths of the three variables from any given initial values. The model is of economic interest because the equations make sense as representations of properties of a real economy that is not subject to any exogenous cyclical shocks, but the time paths of the solution are cyclical. If this modelling exercise is to fit into Morgan's schema, it seems that we must say that 'the model' is the three equations, 'the kind of stuff the model is made from' is mathematics, and the 'manipulation' is finding the solution to the equations. But the distinction between the model and its manipulation seems unhelpful here. The equations define the time paths of the variables; the cyclical paths are just as much the model as the equations are. Once Frisch has written down the equations, the solution has only to be found.

This point can be made even more plainly in relation to the NewlynPhillips Machine. Here, presumably, 'the model' is the system of tanks, pipes, and valves. As Morgan says, "the circulation and manipulation of the flows of water representing the flows of money are governed by the hydraulics" (p. 227). But 'the hydraulics' are just properties of the physical system; they are not actions taken by the modeller. Morgan has to say that putting the "manipulable resources" of this model to work is nothing more than switching on the Machine (p. 226, 14n).

It is perhaps significant that several of Morgan's leading examples of models do not define their own 'solutions' in the way that Frisch's model does. Take the Edgeworth Box. As understood by most economists, this is a two-dimensional diagram that can describe endowments and preferences in a two-person exchange economy. It does not specify what those individuals actually do, or what counts as an equilibrium solution. To derive any conclusions about the pattern of trade in the model, one has to add additional assumptions, for example that trade takes place at market-clearing prices, or that 'blocked' trades do not take place. If one treats the Edgeworth Box 
diagram as 'the model', the way it is used in economics fits Morgan's schema; adding assumptions about individual behaviour or specifying a solution concept can then be characterised as 'manipulation'. But my sense is that economic theorists would be more inclined to say that, until those components are added, the Edgeworth Box is not a fullyspecified model; it is only an extremely useful modelling component.

By treating models as things to be manipulated, Morgan's schema encourages us to overlook the sense in which, even from the viewpoint of its own designer, a model is autonomous. As a modeller, I think of myself as constructing something that has a life of its own: having constructed it, I sit back and watch what it does. Viewed in this way, what is remarkable about the world in Frisch's model is that it is a self-contained economy that generates its own cycles, through the workings of the mechanisms that are described by the model's equations. Having seen that Frisch's model economy has endogenous cycles that are similar to those we observe in real economies, we come to think that the real cycles might be caused by mechanisms similar to those of the model. But to think in this way, we have to see the model cycles as the product of the workings of the model, not of the modeller's manipulations.

Morgan's emphasis on the manipulability of models may be connected with what, for me, is the main limitation of her analysisthe thinness of its account of how models are informative about the economic world that they represent. Although she repeatedly says that models are used to answer questions about that world, she is remarkably reluctant to explain how they do this. How models help us to understand the world is "a messier problem that I return to shortly" (p. 31), "a much more difficult problem" (p. 33), "a very tricky topic to which I return" (p. 237), "a particularly thorny problem" (p. 392), and so on. But, as far as I can see, she does not offer a solution to the problem, beyond such vague formulations as "they [economists] trust that their models will capture some of the heart of the matter" (p. 246) or

narratives operate as a cognitive bridge between the abstract and still relatively general model with its demonstrations and the much more detailed accounts of the concrete events of the real economic world. In making these correspondence links, narratives offer potential explanations for these real-world events (p. 244). 
Morgan seems to want to say that the explanation of real-world phenomena is only a secondary concern of modelling. Recall that in her schema, any such explanatory claims are contained in the 'narrative' of step 4. Describing her experience of listening to economists presenting models, she says:

Narratives occurred primarily in economists' explorations into the world of the model [...] Of only secondary importance was that they provided the format for making informal or casual inferences from the model experiments to the events of the economic world (pp. 361-362).

At best, it seems, models provide only informal, casual, or potential explanations; any confidence in these explanations is a matter of trust.

I have to admit that much of my experience of economists' presentations is similar to Morgan's. But if explanation really is only a secondary concern of modelling, what in economics serves as a formal, rigorous or actual explanation of the concrete events of the real world? If I have read her correctly, her answer is 'econometrics'.

Almost at the end of the book, she says:

No doubt, there were both descriptive and analytical aims for the early economists who created models, but there came a marked divergence after the interwar period so that statistical (econometric) modellers concentrated on theoretically informed descriptions that could be used for measurement and hypothesis testing, while mathematical modellers concentrated on providing accounts that established concepts and sparked hypothesis formation and theory development (p. 388).

It is not clear what Morgan means by "theory development" here, given her (I think correct) claim that modelling has become the primary way of doing economic science. If modelling is what economists mean by theory, how can there be a stage of theorising that progresses beyond modelling? It is easier to understand the claim that economics engages with the real world through econometrics. Presumably, econometrics is "theoretically informed" when it is informed by the kind of modelling that is the subject of Morgan's book. But how do models provide information to econometricians, unless there is some reason to expect similarities between properties of models and properties of the real world? I cannot see how the practice of modelling can have scientific value unless models can provide genuine explanations of the phenomena of the real world. 
Robert Sugden is professor of economics at the University of East Anglia (UK). His research uses a combination of theoretical, experimental, and philosophical methods to investigate issues in welfare economics, social choice, choice under uncertainty, the foundations of decision and game theory, the methodology of economics, and the evolution of social conventions. He is the author or editor of eight books, including The economics of rights, co-operation, and welfare (2005 [1986]) and Experimental economics: rethinking the rules (2009, with five co-authors). He is currently working on a book on contractarian welfare economics.

Contact e-mail: <R.Sugden@uea.ac.uk> 